\title{
Historadiographic studies of lung structures
}

\author{
G. F. GARUSI, S. MORETTI, AND A. BORGHI \\ From the Institute of Radiology, Bologna University, Italy
}

Although there have been new historadiographic techniques, especially in the last 20 years, little attention has been paid to the study of pulmonary tissues. This is surprising because the pulmonary parenchyma has a structure suitable for the application of the historadiographic method. Indeed, whereas in a compact tissue $x$ rays give only a little natural contrast due to slight differences in the chemico-physical make-up of the components, the discriminating power of historadiography is considerably greater in the lung, due to structural features which favour viewing and an appreciation of even the finest details.

The differential absorption of $x$ rays by the histological components is in direct proportion to the absorption coefficient of the mass and grows proportionately with the increase in atomic weight of the various biological structures and with the lengthening of the radiation waves employed. It is therefore easy to understand how the different densities of the broncho-vascular elements and of the alveoli, with their dense network of collagenous and elastic fibrils, surrounded by gaseous contrast, constitute ideal conditions for the use of long-lambda radiations. The results are likely to be even more interesting when dust or any compound with a high atomic number is deposited and when pathological alterations are found with the formation of granulomatous tissue and fibrous bands.

The important characteristics of historadiography are as follows: $(a)$ The microradiographic images are expressions of the physico-chemical composition of the different constituents, unlike the appearances seen in normal microscopy, where the structures are differentiated by their various staining reactions. (b) There is a greater depth of field compared with that of the optical microscope, and it is possible to study sections which are largely opaque to transmitted light. (c) The historadiographic picture, like the ordinary radiogram, represents a 'negative' instead of a 'positive' of the microscopic view of the preparation; its interpretation therefore requires an experienced eye, and this is obviously facilitated by comparison with the corresponding histological pictures.

\section{TECHNICAL NOTES}

Previous microradiographic work has been done by Oder, Pizzolato, and Ziskind (1958) in the study of pulmonary emphysema. Their studies, however, were carried out on relatively thick sections of pulmonary parenchyma, which had been perfused and dried; this method permits a so-called panoramic study of pulmonary tissue with clear viewing of its architecture. Our work has been of a more histological nature, using thin sections (4-5 $\mu$ ), with low radiographic voltages, in order to investigate the fine alveolo-septal structures and the interposed broncho-vascular elements.

Suitable techniques for the lung have already been described by several authors. Distension with an aqueous $20 \%$ formalin solution at a pressure of 25 to $30 \mathrm{~cm}$. and fixation for several days was the method of Heard (1958). Formaldehyde gas was used for inflation and fixation at a pressure of 40 to $50 \mathrm{~mm}$. $\mathrm{Hg}$ by Cureton and Trapnell (1961).

As far as technique is concerned, we availed ourselves of the Philips CMR 5 set, using contact microradiography; the technical data employed were the following: $1 \cdot 8-2 \cdot 2 \mathrm{kV} ; 2 \mathrm{~mA}$; 4-8 min. per exposure.

The radiographic emulsion used was Kodak experimental film V 6028, kindly supplied by the Harrow Laboratories, with Kodak D 158 developer.

The tissue is embedded in paraffin and histological sections, 4 to 5 microns thick, are cut with a common microtome. The preparations are laid on a very thin film of terephthalate ${ }^{1}$; they then go through a prolonged wash (1 to 2 hours) in xylene to eliminate all traces of paraffin, which might greatly disturb the microradiographic picture. A last run is made through pure alcohol (1 minute) to dehydrate the slices so as to avoid later shrinkage, from heating during exposure to the rays, and consequent blurring of the images.

Subsequently the slices mounted on the terephthalate are placed on the metal discs, supplied with the set, which serve as limiters with a central exposure hole to the radiant beam of about $3.5 \mathrm{~mm}$. On this support the slices are fixed with a little gum at the edges, centering with the microscope the most interesting zone to be examined. In the dark-room the limiter with the preparation is placed on the small disc of film, already prepared, and both are placed on the carrier, the latter also being supplied with the set.

\footnotetext{
1 Montivel, supplied by Montecatini, Milan, Italy
} 
Since the histological preparation is dehydrated, it should be put in immediate contact with the radiographic emulsion so as to reduce as much as possible the shading effect of the images and the filtration of softer rays.

All these steps should be carried out carefully, avoiding above all the superimposition of dust.

After exposure to the $x$ rays, the film disc is developed and fixed in the usual way, using pincers. The films are catalogued and the corresponding histological preparations are kept, in case a repetition of the examination should be necessary with modified technical data. The film discs are then inserted in a small rack and placed to dry under a glass bell. The historadiographic pictures are subsequently examined under the microscope and photographically reproduced with suitable enlargements. The Kodak V 6028 film, considerably more sensitive than Kodak Maximum Resolution, has remarkable uniformity of distribution of the bromide granules of $\mathrm{Ag}$ and has high resolvent powers, such as to allow useful enlargements of up to about 1,000 diameters (Blackett, 1958).

\section{THE PRESENT STUDY}

The object of the present research was the historadiographic study of histological sections of numerous lungs, some healthy and some affected by various pathological conditions such as inter- stitial fibrosis, bronchitis and peribronchitis, $\stackrel{\vec{F}}{+}$ amorphous calcified deposits, interstitial calcinosis, $\bar{c}$ silicosis, and pneumoconioses of various kinds.

Our investigations are only of a qualitative $\frac{\bar{\omega}}{\sigma}$ nature and are intended to illustrate the possi- $\mathbb{\mathbb { Q }}$ bilities inherent in the historadiographic method, employing the simplest apparatus available to-day. This is within the reach of any research laboratory and there is no need to have complicated and $\vec{\omega}$ expensive apparatus which but few specialized $O$ institutes possess.

The sections of alveolar tissue taken from well- $\stackrel{x}{\vec{\theta}}$ inflated pulmonary lobes look like a fine net in historadiography; the interalveolar septa, seen ir with higher magnification, have a delicate 'knitted' $\vec{\circ}$ design made up of transverse sections of the capillaries pressed closely one against the other. $\vec{c}$ The walls of the capillary vessels and the interposed collagen fibres appear considerably radioopaque ; this is more evident when moderate interstitial fibrosis also is present, as in Fig. 1. A study $\vec{\bullet}$ of sections of small bronchi shows the structure of the cartilaginous rings, the lining mucosa, sometimes with small glands, the submucous tissue, and the small arterial and venous satellite vessels (Fig. 2).

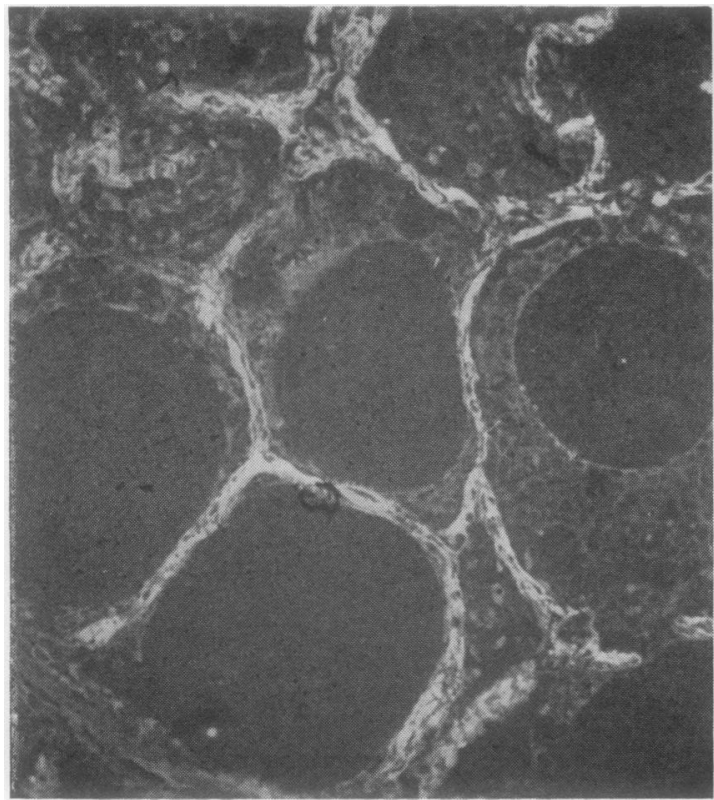

(a)

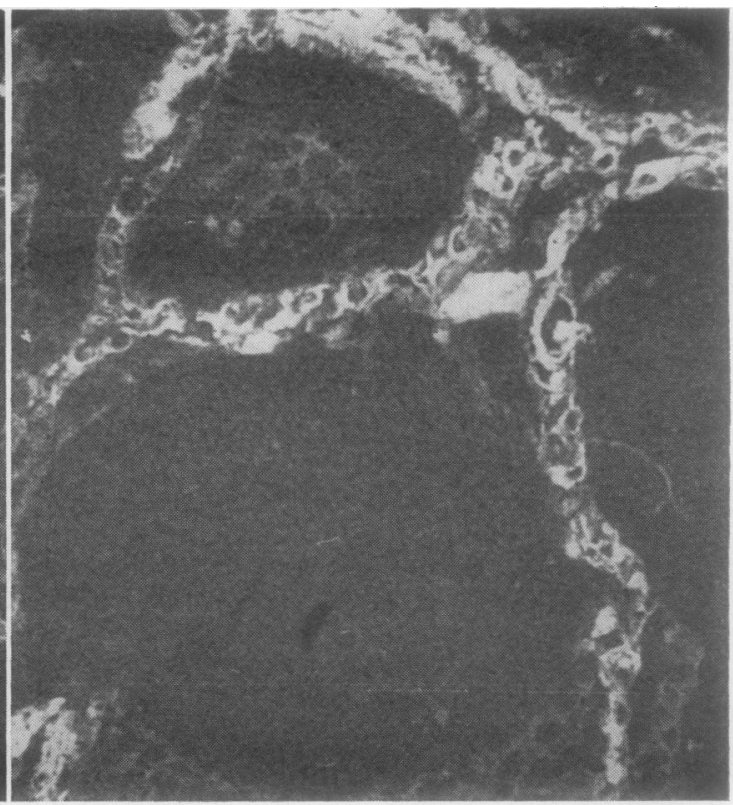

(b)

FIG. 1. Pulmonary parenchyma. (a) The alveoli appear distended, partly filled with fibrin, with vacuoles and wider $\stackrel{\mathbb{D}}{\circ}$ bubbles. The interalveolar septa show remarkable density due to interstitial fibrosis ( $\times 65)$; (b) On higher magnifica- $\mathbb{D}$ tion a fine 'knitted' structure can be seen caused by the images of the transverse sections of the capillaries, tightly 0 pressed one against the other $(\times 210)$. 


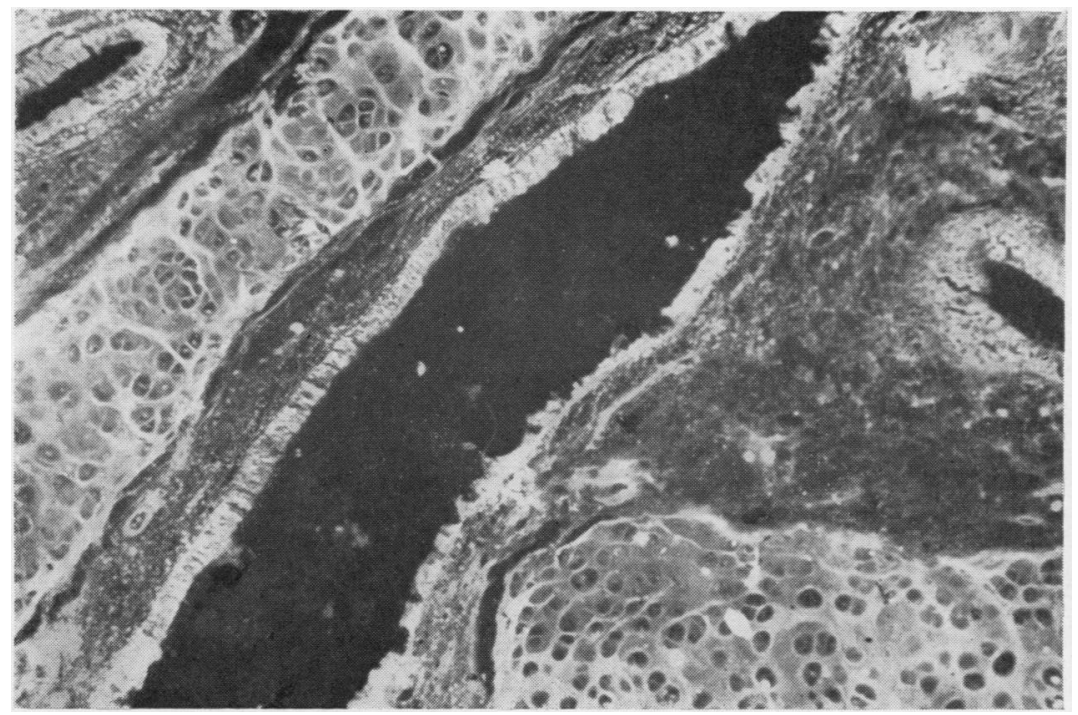

FIG. 2. Historadiographic image of a section of small normal bronchus. Note the clear view of the cartilaginous cells and the epithelial lining of the bronchus, as well as the small vessels and the adjacent structures.

A completely different picture is seen in the various stages of emphysema and chronic bronchitis with peribronchial fibrosis. The normal net design of the alveolar septa appears altered in these cases, or often totally distorted, with septa lacerated and intermixed with dense bands of fibrotic thickening that are quite radio-opaque (Fig. 3 a, b). The bronchi are seen often surrounded by granulomatous tissue, their walls being considerably thickened with dense collagen fascia arranged in layers and with reduction of the lumen; morphologically amorphous calcareous deposits are frequently seen (Fig. $3 \mathrm{c}$ ).

There were some interesting findings in a patient with diffuse interstitial calcinosis of the lung. Here the normally aerated lobules showed the usual appearances of pulmonary emphysema, but in other zones the interalveolar septa showed scleroconnective thickening and appeared selectively contrasted due to the deposition of radio-opaque material of calcareous density. At certain points the calcium was collected in granules or in small masses, while in others it assumed a trabecular appearance, affecting especially the capillary walls and the middle layer of the small vessels (Fig. $4 \mathrm{a}, \mathrm{b})$.

Figure $4 \mathrm{~d}$ shows, in the same patient, an island of deposition of calcareous salts within a bronchial cartilage; within this calcified zone the nuclear images of the cartilaginous cells are still clearly visible. .Histochemical analyses (Prof. G. Giunti and A. Ganassi) showed that these calcareous salts were for the most part composed of phosphates.

An interesting part of this work is seen in the study of silicosis and pneumoconiosis in general. Although the histopathological aspects of the pneumoconioses are well defined, not much is known of the distribution of the mineral particles in the tissues. Indeed, common histological methods are inadequate to show up the mineral crystalline aggregate. The polarized light and the phase-contrast techniques, though able to show the presence of doubly refractile substances, cannot tell their exact nature or demonstrate their topographical relations. Microincineration technique with subsequent spectrometry permits a fine qualitative evaluation of the mineral elements contained in them but does not make it possible to ascertain the manner of their aggregation and, above all, of their topographical distribution within the tissues. It has, however, been possible for us to carry out this study by using the historadiographic method.

The physical characteristics that regulate the formation of microradiographic images make immediate viewing of the crystalline mineral aggregates particularly easy because of their high atomic weight. This does not require prolonged and difficult colouration methods or subtle manoeuvres which may sometimes alter the substratum being examined.

In our pictures of silicotic lungs, images suggestive of rather radio-opaque, crystalline- 

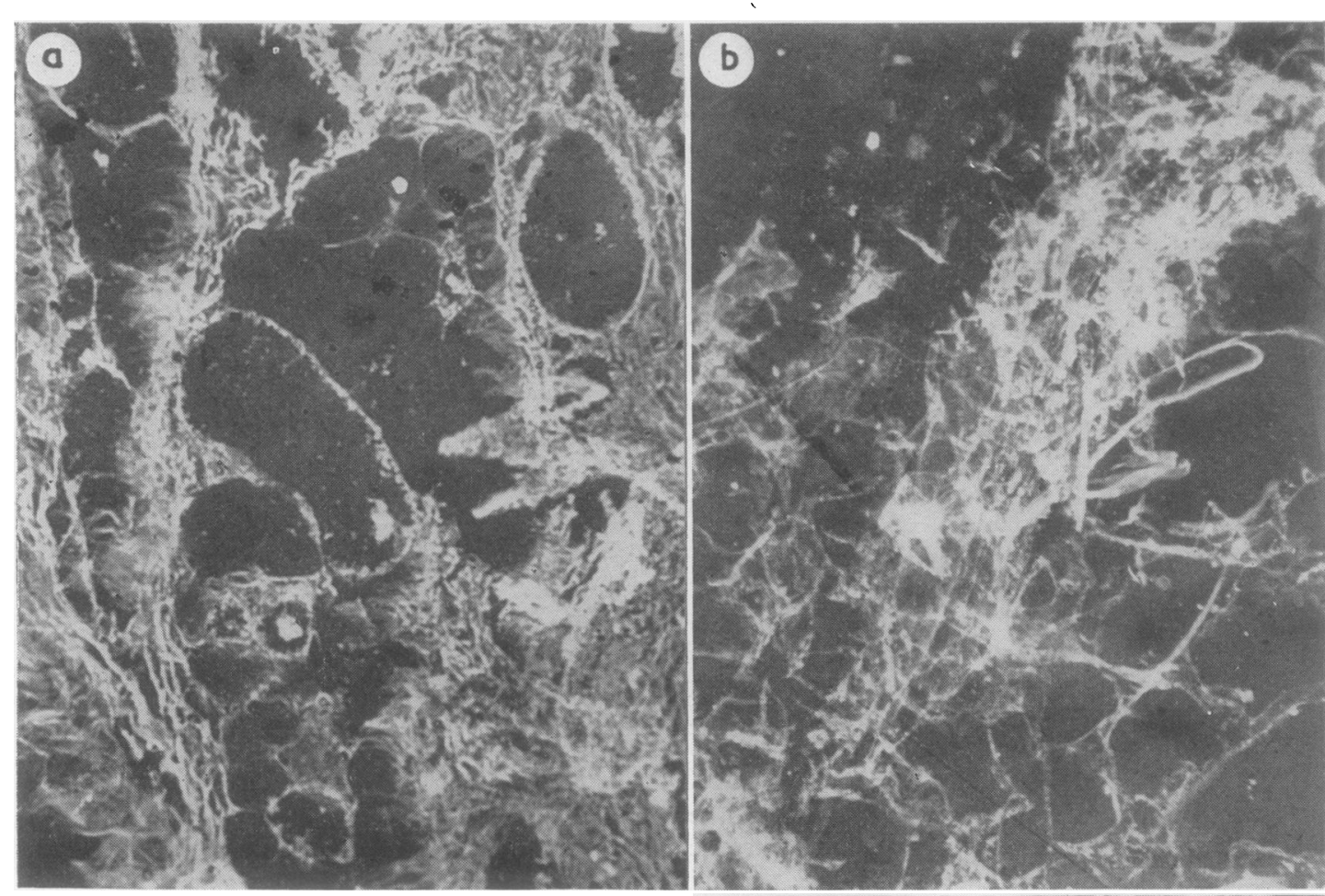

FIG. 3. Diffuse senile emphysema with peribronchial fibrosis. $(\mathrm{a}, \mathrm{b})$ Total alteration of the normal parenchymal design; the interalveolar septa are partly lacerated with diffuse thickening and large fibrotic strips $(\mathrm{a}, \times 80 ; \mathrm{b}$, $\times 100$ ); (c) section of small bronchus with vessels; note the conspicuous and diffuse fibrotic thickening of the walls and of the interstitial stroma $(\times 100)$.

looking masses can be seen, with a different morphological appearance and manner of grouping in the field of the silicotic lesions.

Indeed, the localization of these crystalline images around the small vessels and the bronchioli almost suggests an attempt at drainage through the lymphatic spaces (Figs. $5 \mathrm{c}, \mathrm{d} ; 6 \mathrm{c}, \mathrm{d}$; and $7 \mathrm{a}, \mathrm{b})$. At other times the mineral masses are situated at the periphery of the silicotic nodules (Fig. $5 \mathrm{a}, \mathrm{b}$ ) or on the edge of the ulcerative cavities (Fig. $6 \mathrm{a}, \mathrm{b}$ ); in fact these formations hardly ever appear isolated but always tend to group together, even if in different ways.

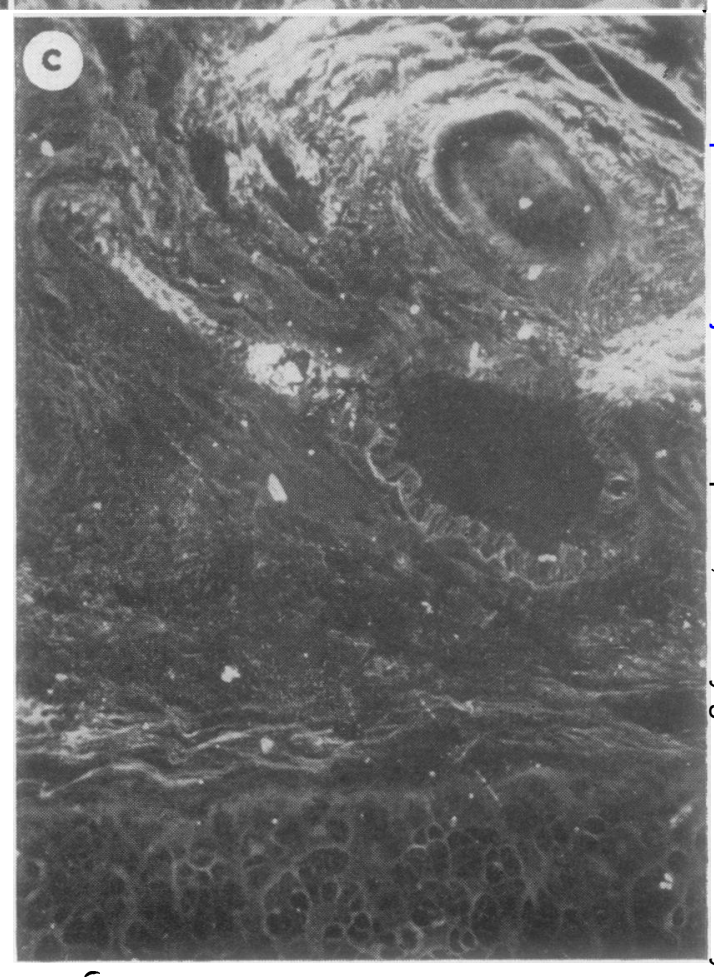



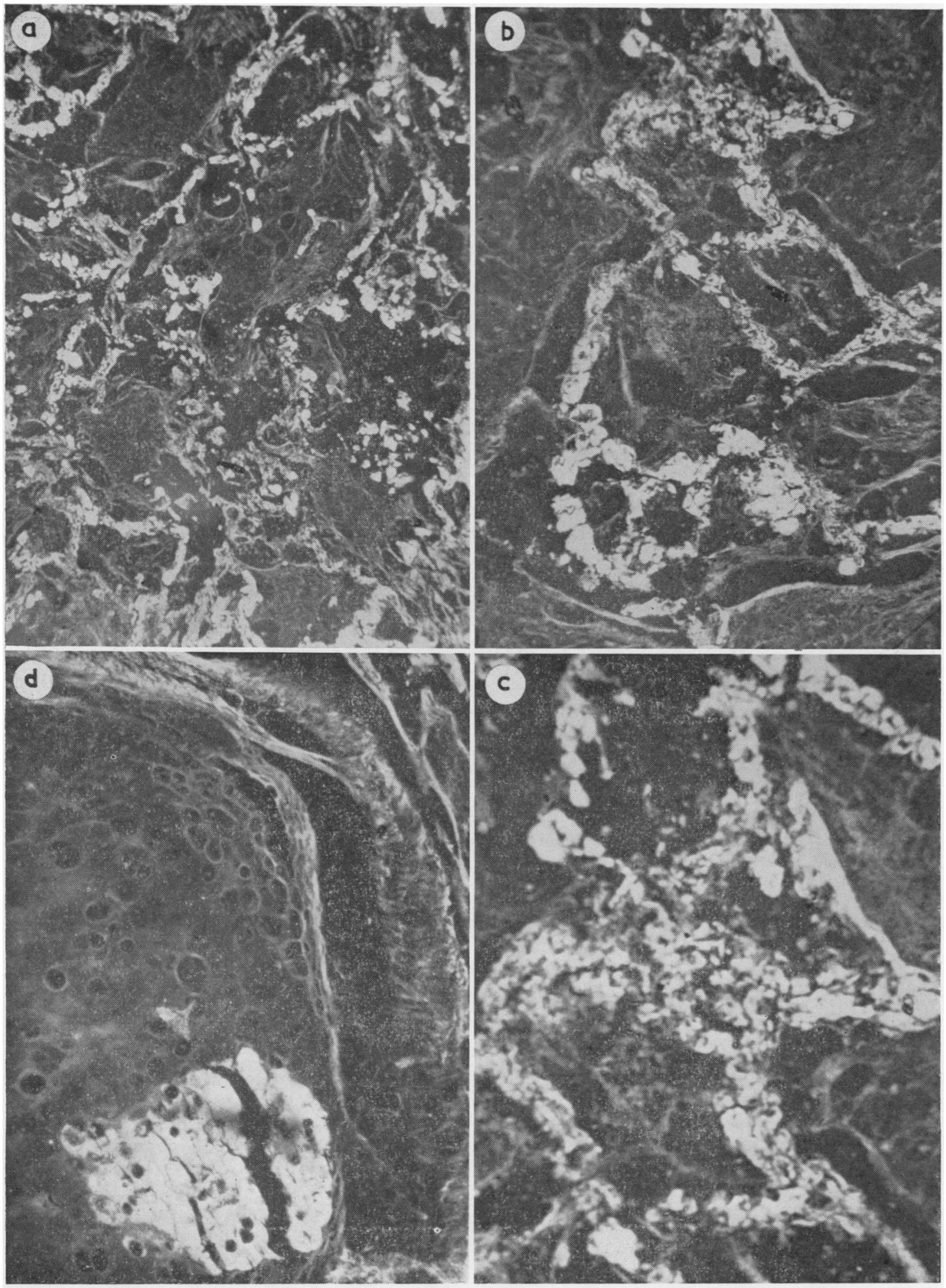

FIG. 4. Interstitial pulmonary calcinosis. (a, b, c) The interalveolar septa are thickly and selectively packed with calcareous deposits with a fine design and irregular network (a, $\times 80 ; \mathrm{b}, \times 180 ; \mathrm{c}, \times 250)$; (d) image of bronchiolar cartilage in the same patient, showing a large calcified island within which the nuclei of the cartilaginous cells can still be seen $(\times 100)$. 

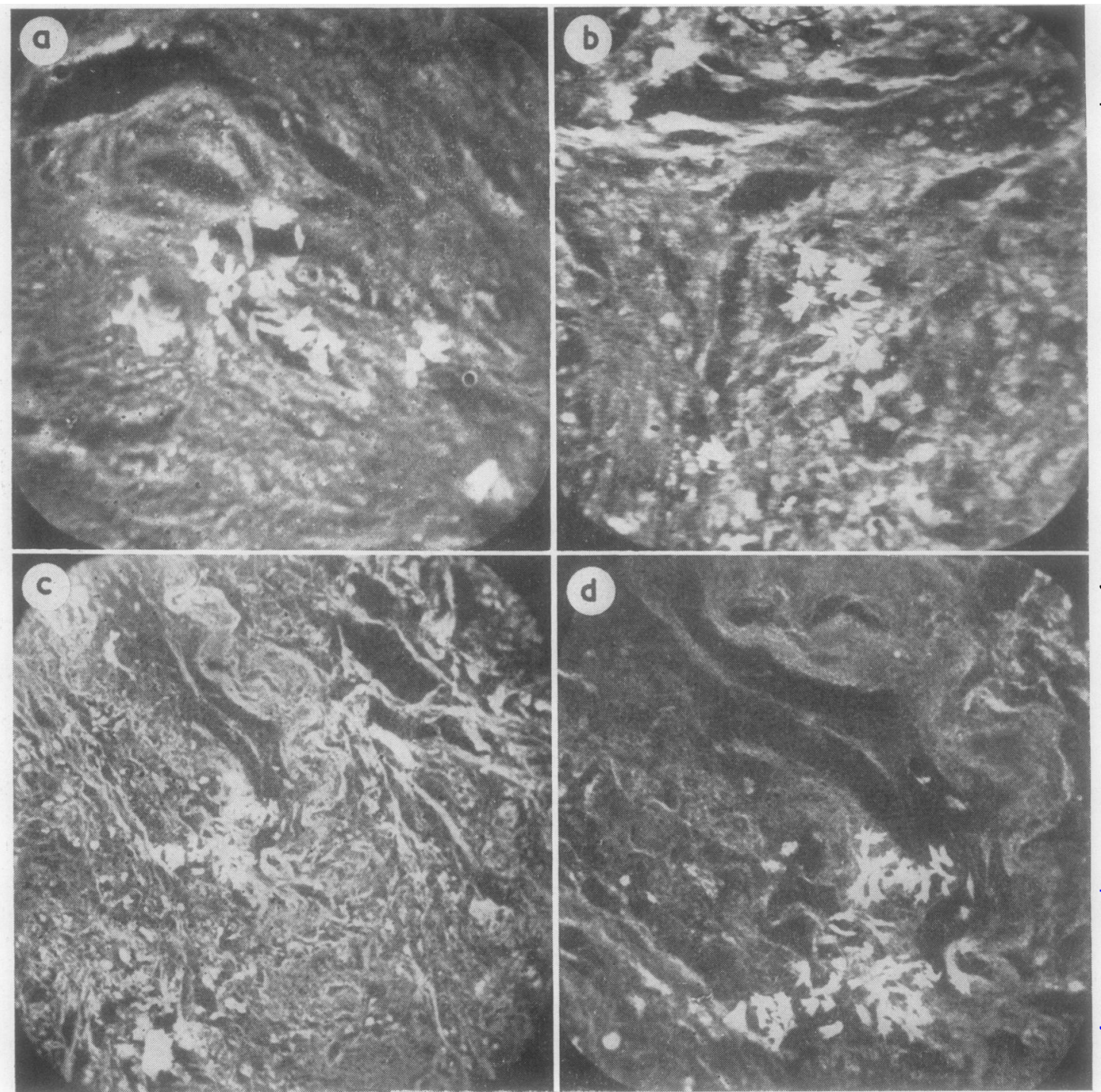

FIG. 5. Pulmonary silicosis. (a, b) Images of small masses of crystalline elements, arranged star-shaped, situated $\stackrel{ }{2}$ towards the border of silicotic nodules $(\times 120) ;(\mathrm{c}, \mathrm{d})$ non-homogeneous structure of the granulomatous tissue with $\frac{7}{0}$ differing distribution of the radio-opaque elements $(\mathrm{c}, \times 80)$. Grouping of the crystalline formations around a small bronchus is more clearly seen $(\mathrm{d}, \times 120)$.

The morphological aspect of these images is undoubtedly similar to that of mineral aggregates in the crystalline state, such as the diverse types of crystals of silicon compounds that can be seen in the laboratory, even if their direct qualitative identification is not possible. This is probably because the action of the organic liquids and the enzymes may in time even considerably modify the morphology of the mineral crystals inhaled and passed into the tissues.

In our pictures the crystalline images are clearly seen in the granulomatous tissue due to the intense ${ }_{N}^{\circ}$ radio-opacity. They may be shaped like a small $\omega$ stick (Figs. 5 and 6) or needle-shaped (Fig. 8), and the different way of combining creates different patterns (Figs. $5 \mathrm{~b}, \mathrm{~d} ; 7$, and 8). One ${ }_{\overparen{\infty}}$ of our patients had worked in a limestone and ${ }^{+}$ silica mine (Fig. 8), others in granite quarries (Figs. 5, 6, 7).

The mineral substances in the lung samples investigated by diffractometry showed the $\varrho$ characteristic lines of quartz; with spectrometry 
of the ashes, it was possible to see a considerable quantity of silicon, calcium, magnesium, and aluminium.

In other kinds of pneumoconiosis (for example, anthracosis and siderosis) the historadiographic picture showed masses of radio-opaque nodular images, without a characteristic morphology, arranged in strips or grouped in fairly uniform zones, looking like a mosaic, situated within the granulomatous tissue (Fig. 9 a, b).

In the pulmonary zones where emphysema is prevalent the mineral deposits are collected in bands and morphologically amorphous aggregates which clearly stand out among the residue of the thickened and mostly lacerated interalveolar septa (Fig. 10).
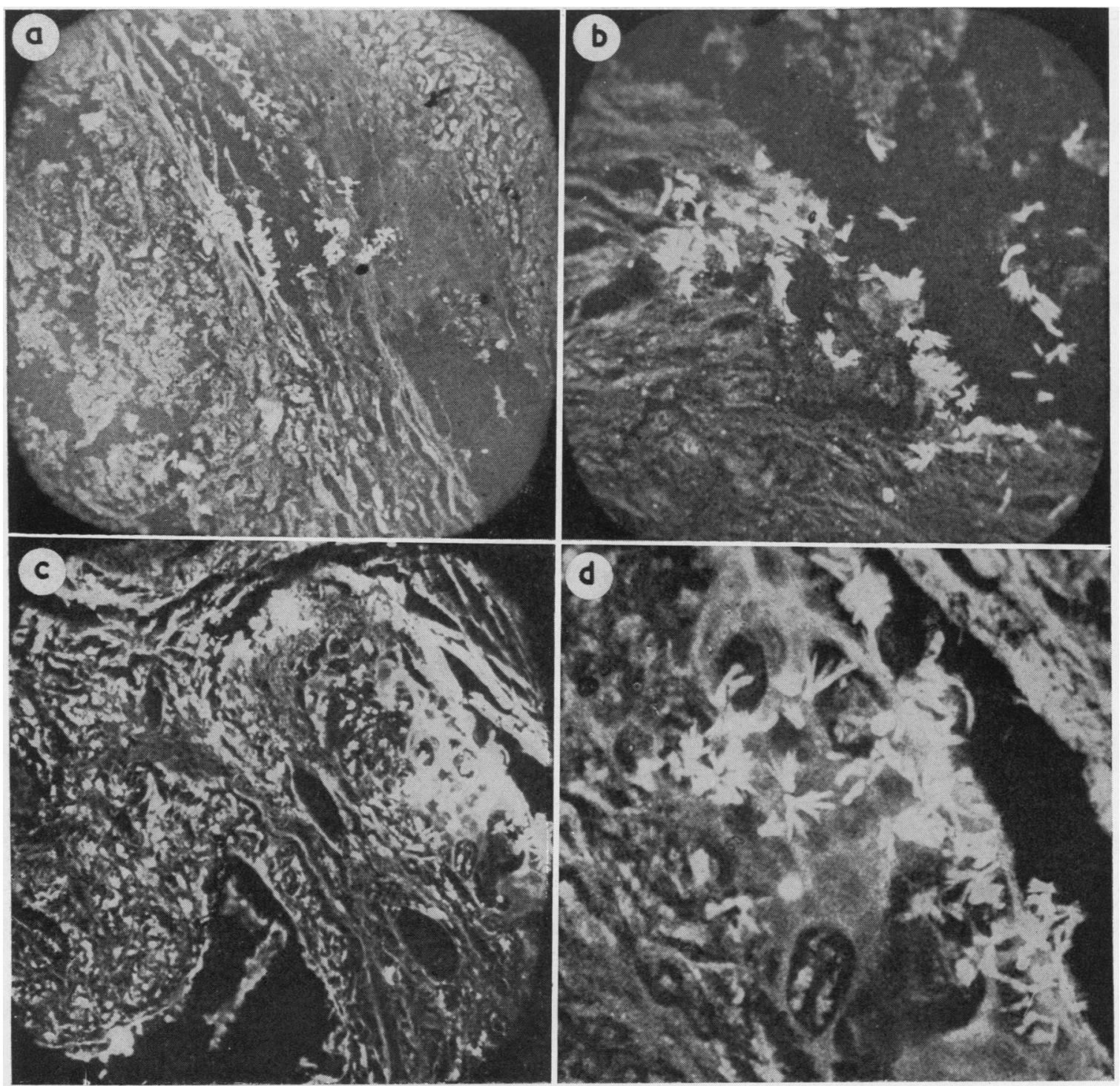

FIG. 6. Pulmonary silicosis. (a, b) Images of intensely opaque crystalline formations arranged between the fibrous bundles $(\mathrm{a}, \times 50)$ and, above all, gathered on the edge of an ulcerated formation $(\mathrm{b}, \times 120)$; (c) granulomatous tissue with small irregular amorphous calcareous deposits $(\times 100) ;(\mathrm{d})$ needle-shaped crystalline images collected in the vicinity and on the edge of a small bronchus $(\times 300)$. 
FIG. 7. Pulmonary silicosis. (a) Selective accumulation of crystalline mineral formations around a vessel wall $\vec{\oplus}$ probably contained in the perivessel lymphatic space $(\times 80)$; (b) on higher magnification the crystalline elements show an image suggestive of 'tuft' or 'sparks' and assume a 'Cross of Malta' appearance $(\times 600)$.
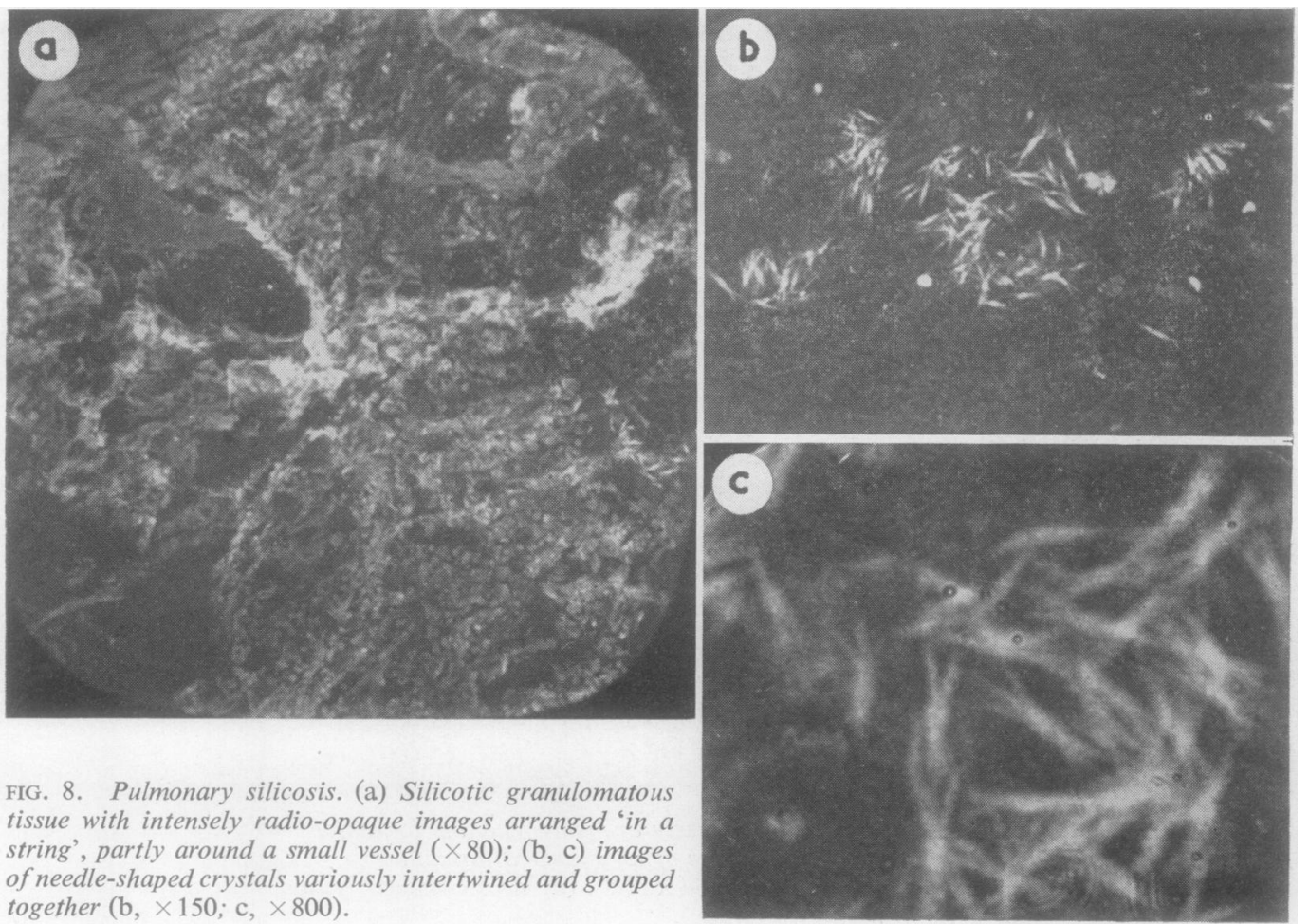

FIG. 8. Pulmonary silicosis. (a) Silicotic granulomatous tissue with intensely radio-opaque images arranged 'in a string', partly around a small vessel $(\times 80)$; $(\mathrm{b}, \mathrm{c})$ images of needle-shaped crystals variously intertwined and grouped together $(\mathrm{b}, \times 150 ; \mathrm{c}, \times 800)$. 


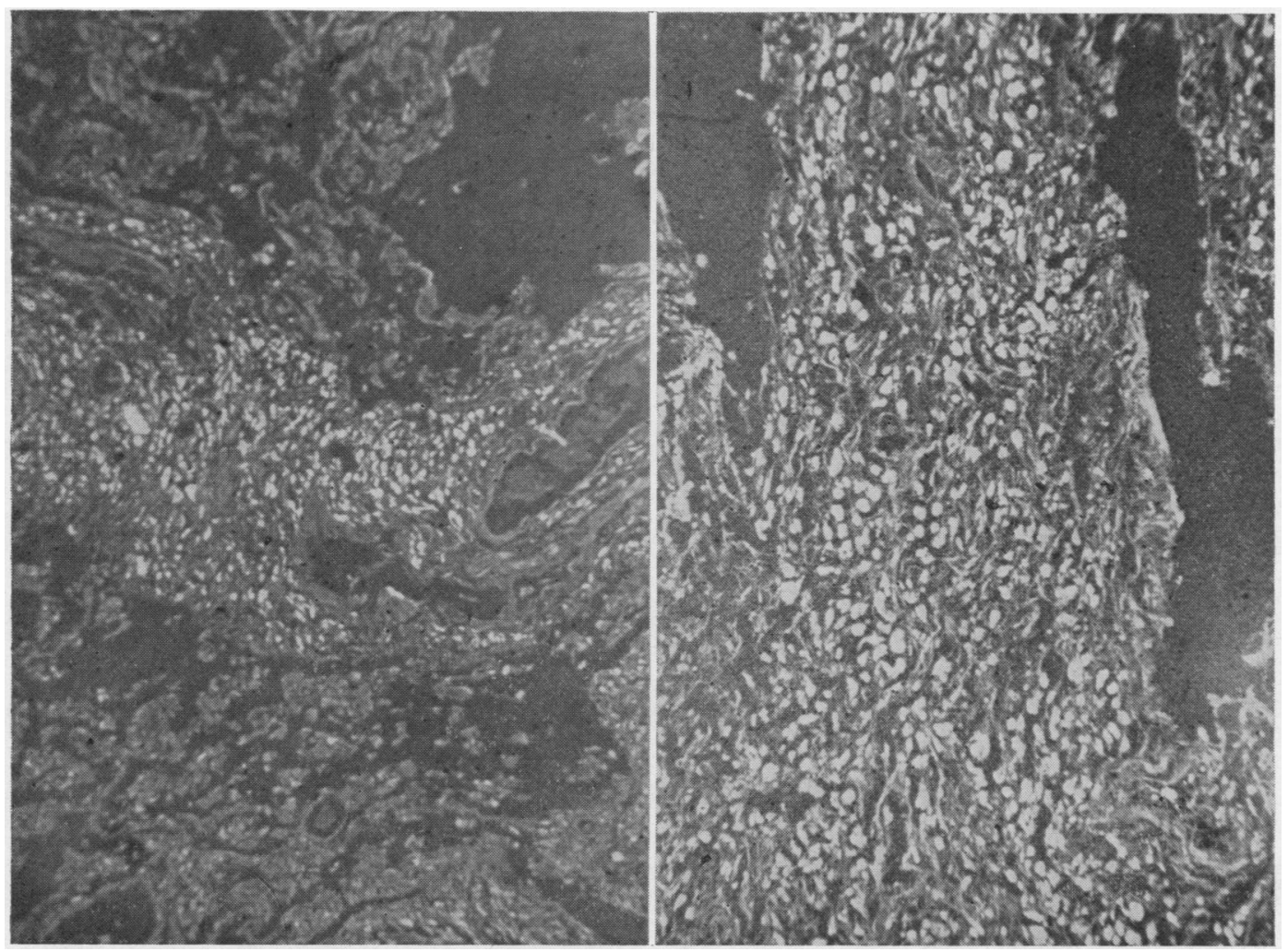

FIG. 9. Pneumoconiosis. In the context of a markedly altered, partly organized pulmonary tissue, an extensive area of radio-opaque granules, gathered as in a mosaic pattern, is seen $(a, \times 80 ; b, \times 200)$.

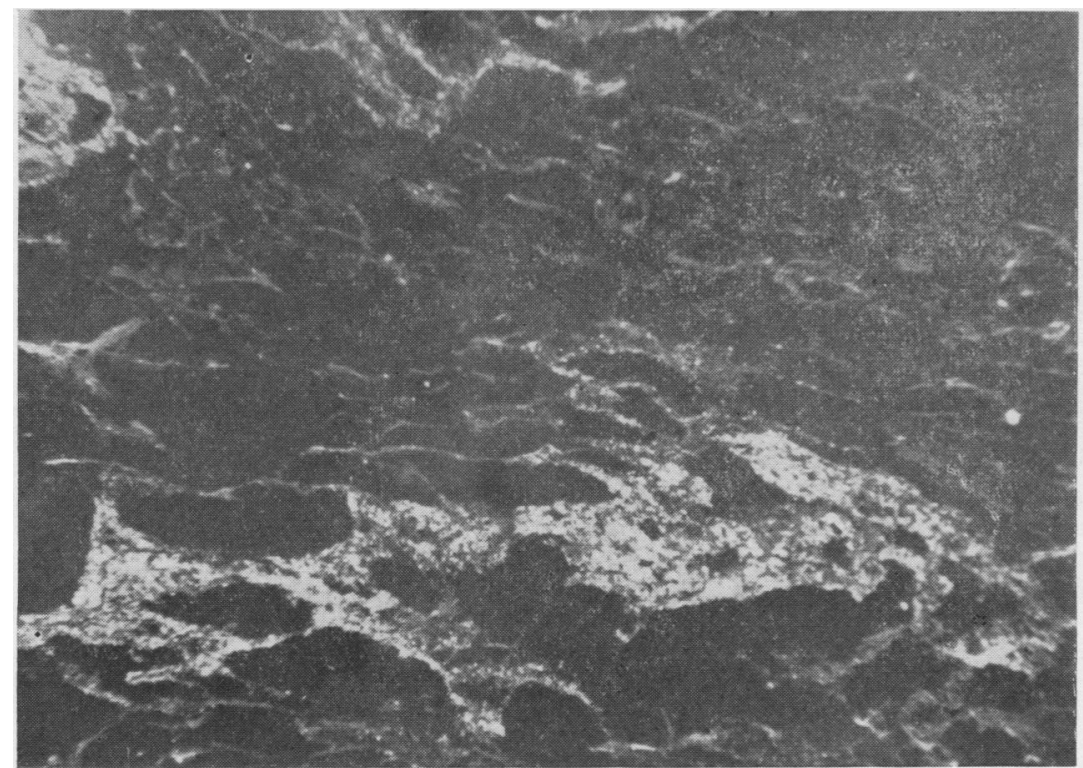

FIG. 10. Pneumoconiosis. Diffuse emphysema with disappearance of normal alveolar design; a strip of irregular, considerably radio-opaque thickening is seen in the centre $(\times 120)$. 


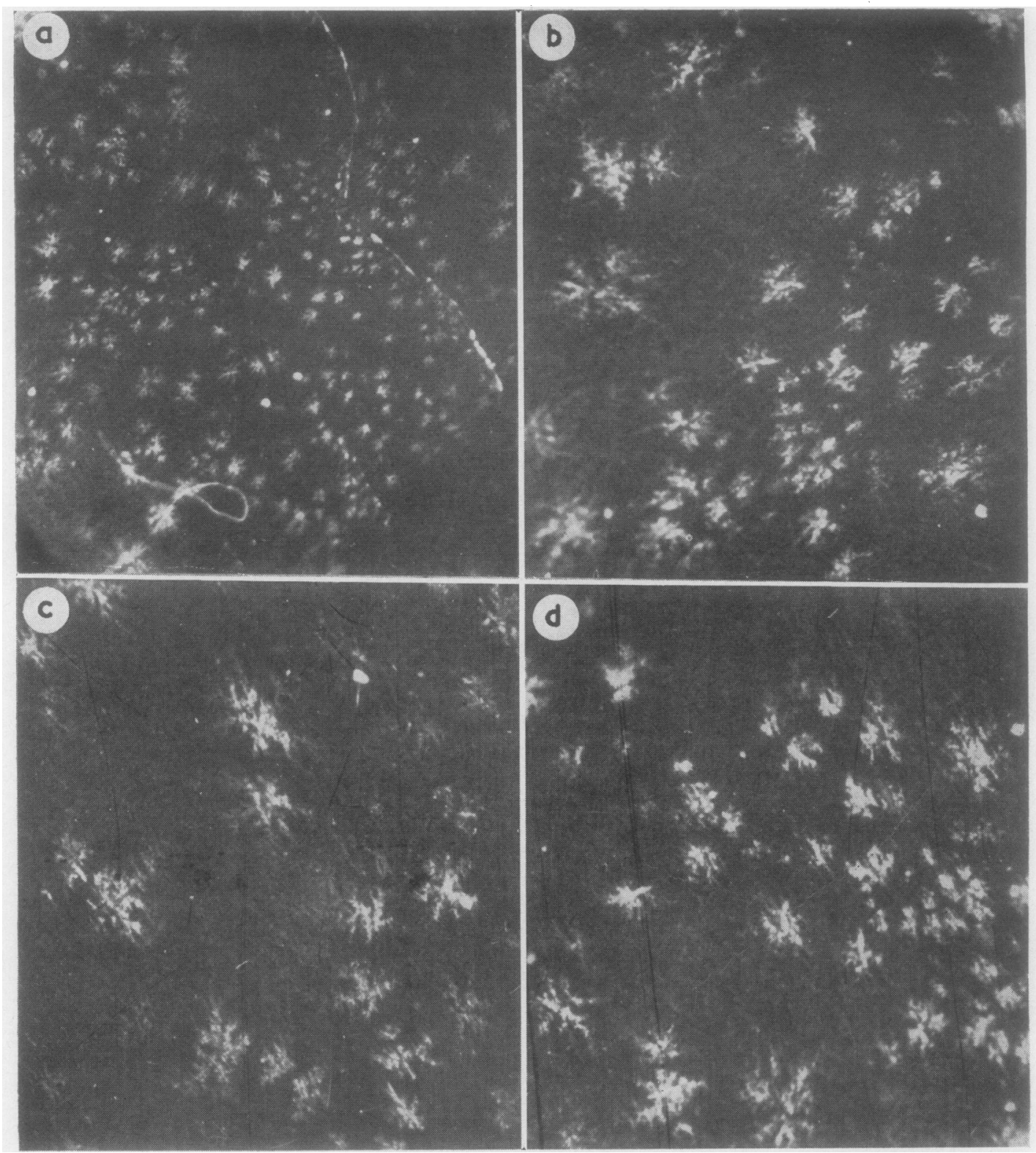

FIG. 11. Pneumoconiosis. Historadiographic pictures obtained by using higher voltage (4-5 $\mathrm{kV} ; 2 \mathrm{~mA} ; 30$ $60 \mathrm{sec}$.$) to throw up the mineral formations more clearly. On the dark background there are numerous intensely$ radio-opaque images, which at a lower magnification $(\mathrm{a}, \times 60)$ have the appearance of stars while at a higher magnification they recall the form of snow crystals $(\mathrm{b}, \mathrm{c}, \mathrm{d}, \times 150)$.

There was a rather suggestive finding of uncertain interpretation in a patient with pneumoconiosis of unknown type. While carrying out historadiography in areas of compact and carnified pulmonary tissue by means of slightly more penetrating radiations, so as to make the mineral deposits stand out better on the dark field of the granu- lomatous tissue, we noticed the dissemination of a very large number of small, very radio-opaque, star-shaped images (Fig. 11). At a higher magnification these formations have an appearance like that of snow crystals (Fig. $11 \mathrm{c}$, d) and, due to their characteristic distribution, suggest mineral dust deposits in centrilobular (lymphatic?) spaces. 
FIG. 12. Bronchiectatic lung. $A$ residue of iodized oil from $a$ previous bronchography $(\times 70)$.

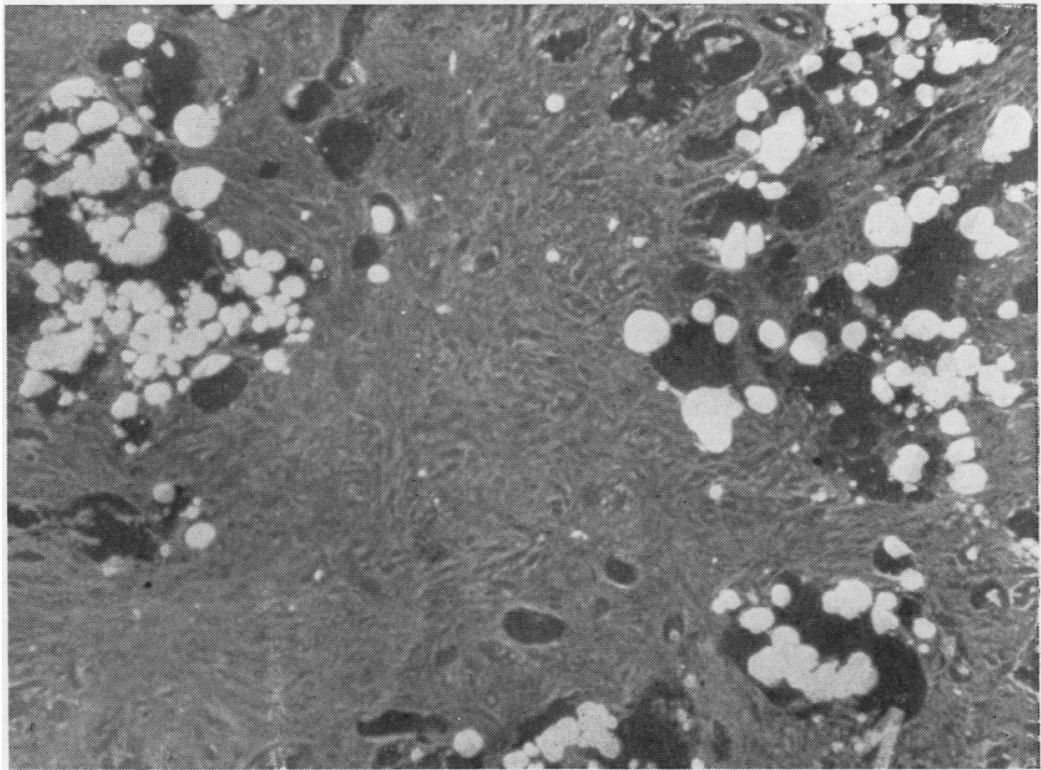

This is, of course, only a hypothesis for which we possess no proof; what we can say is that the lung preparation examined was not treated with any substance that might bring about such artefacts and that these images must therefore correspond in some way with the pneumoconiotic process.

Historadiography is useful in intraparenchymal ossification (as in alveolar microlithiasis and mitral stenosis), pigment deposits (haemosiderosis), certain hamartomas with skeleton elements, and partly calcified cystic formations, as well as in neoplastic processes with possible calcareous deposits.

Finally, the distribution of possible residue of contrast medium after bronchography may be conveniently studied with historadiography, as is shown in Fig. 12, where small drops of iodized oil are clearly seen in small bronchiectatic cavities.

\section{SUMMARY}

A historadiographic method, using the technical principle of contact microradiography (CMR), has been used to study pulmonary tissue, both normal and altered by various types of pathological processes.

The histological preparations are made by a simple method and without any artifice that might create false images.

The historadiographic picture, in accordance with the physical laws of absorption of long-wavelength $x$ rays, is dependent on the atomic weight of the different constituents of the pulmonary tissues.
In silicosis the use of historadiography has made it possible to demonstrate images suggestive of mineral aggregates with a crystalline look. The clear view of these formations (in all probability varying with the aetiological agent) seemed helpful as regards morphology and topographical distribution compared with the silicotic lesions and the broncho-vascular and lymphatic structures. The method may therefore be considered a useful complement to other histological techniques.

We are grateful for the histological preparations to Dr. G. Costanzi (Figs. 1, 5, 6, 7, 8, 11), Professor A. Ganassi (Fig. 4), Professor M. Cresti (Figs. 2 and 12), and Dr. Pappalardo (Figs. 9 and 10).

\section{REFERENCES}

Blackett, N. M. (1958). The resolution obtainable with a commercially available microradiographic unit. Brit. J. Radiol., 31, 368.

Combée, B., Houtman, J., and Recourt, A. (1955). A sealed-off X-ray tube for contact-microradiography. Ibid., 28, 537

Cureton, R. J. R., and Trapnell, D. H. (1961). Post-mortem radiography and gaseous fixation of the lung. Thorax, 16, 138.

Garusi, G. F., and Costanzi, G. (1962). Aggregati cristallini in polmoni silicotici evidenziati mediante microradiografia. Radiol.clin., 31, 157.

Giunti, G., and Ganassi, A. (1960). Considerazioni patogenetiche sulla calcinosi interstiziale diffusa del polmone. Arch. De Vecchi Anat pat $32,547$.

Heard, B. E. (1958). A pathological study of emphysema of the lungs with chronic bronchitis. Thorax, 13, 136.

Oderr, C. P. (1960). Lung structure studied by microradiography. In Engström, A., Cosslett, V., and Pattee, H. (ed.): $X$-ray Microscopy and X-ray Microanalysis: Proceedings of the Second International Symposium (Stockholm, 1960), pp. 290-292. Elsevier, Amsterdam.

Elsevier, Amsterdam. microradiology. Radiology, 71, 236.

Piccaluga, A., and Ganassi, A. (1960). Valutazioni morfologiche, nosografiche ed istopatogenetiche dei fenomeni ulcerativi nosografiche ed istopatogenetiche dei fenomeni ulcerativi nell'evoluzion 